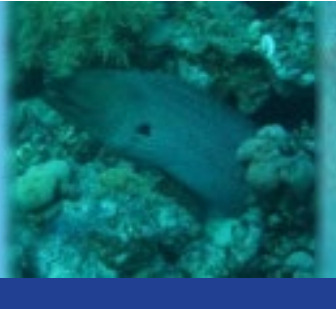

AQUATIC RESEARCH

E-ISSN 2618-6365

\title{
Removal of high concentration of nitrate and phosphate from aqueous mixotrophic solution by Chlorella vulgaris
}

\author{
Tuğba Şentürk ${ }^{\mathbb{D}, ~ S ̧ u ̈ k r a n ~ Y ı l d ı z ~} \mathbb{0}$
}

Cite this article as:

Şentürk, T., Yıldız, Ş. (2020). Removal of high concentration of nitrate and phosfhate from aqueus mixtrophic solution by Chlorella vulgaris. Aquatic Research, 3(1), 13-23. https://doi.org/10.3153/AR20002

Manisa Celal Bayar University Faculty of Science and Art Department of Biology Manisa, Turkey

ORCID IDs of the author(s):

T.Ş. 0000-0002-9882-0079

Ş.Y. 0000-0003-3195-2269

Submitted: 31.10 .2019

Revision requested: 03.12 .2019

Last revision received: 06.10 .2019

Accepted: 09.12.2019

Published online: 12.12 .2019

Correspondence:

Tuğba ŞENTÜRK

E-mail: tugba sen34@hotmail.com

\begin{abstract}
Microalgae exhibit large potential as an alternative to advanced biological nutrient removal in wastewater or simulated wastewater at laboratory conditions. Therefore, it is necessary to determine the optimum conditions for nutrient removal. This study investigated the total carbohydrate, chlorophyll-a, -b, carotenoid and lipid production and nutrient removal of mixotrophic microalgae (C. vulgaris) cultured in different nitrate/phosphate rich modified BG-11 medium (0-200 mg L-1) at longer growth periods (10 days). The mean removal efficiency of $\mathrm{NO}_{3}-\mathrm{N}$ (in nitrate source), and $\mathrm{PO}_{4}-\mathrm{P}$ (in phosphate source) $(88.29 \pm 0.12$ and $31.06 \pm 0.22 \%$, respectively) was reached in the mixotrophic culture. Under the optimum conditions $\left(200 \mu \mathrm{mol}\right.$ photon $\mathrm{m}^{-2} \mathrm{~s}^{-1} 16 \mathrm{~h}$ photoperiod and $28 \%$ inoculum size), 63.61-99.05\% of $\mathrm{NO}_{3}{ }^{-}$and $13.97-63.77 \%$ of $\mathrm{PO}_{4}{ }^{3-}$ were successfully removed. The lipid and carbohydrate productivities were 27.95 and $29.53 \mathrm{~g} \mathrm{~L}^{-1} \mathrm{~d}^{-1}, 0.2869$ and $0.2435 \mathrm{~g} \mathrm{~L}^{-1} \mathrm{~d}^{-1}$ respectively, which were approximately 9-12 times higher than those in photoautotrophic condition. The BG-11 growth media containing $10 \mathrm{~g} \mathrm{~L}^{-1}$ glucose and excessive amount of nutrient effect results indicate that the Chl-a, -b and carotenoid contents of $C$. vulgaris is higher at $100 \mathrm{mg} \mathrm{L}^{-1} \mathrm{~N}$ and $50 \mathrm{mg} \mathrm{L}^{-1} \mathrm{P}$ growth media composition compared to $100 \%$ growth media composition. Thereby, the findings of this study provided an insight into the role of algal uptake of nutrients under the nutrient rich mixotrophic medium for the future algae-based treatment application.
\end{abstract}

Keywords: Bioremediation, Chlorella, Mixotrophic solution, Nutrient removal, Algal removal

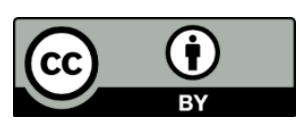

(C) Copyright 2020 by ScientificWebJournals Available online at 


\section{Introduction}

The application of microalgae for wastewater treatment has gained much attention due to the potential of microalgae to simultaneously remove nutrients and produce valuable biomass. Their great potential in producing biodiesel, which is a renewable energy source, can reduce the greenhouse gas emissions (Abe et al., 2008; Khan and Yoshida, 2008; Bruce, 2008; Groom et al., 2008; Azianabiha et al., 2019).

The production of biofuels from microalgae is associated with high demands of nutrients required for growth (Barbera et al., 2016). Their lipid productivity/biomass (dry weight) is about 15-300 times that of conventional crops (Chisti, 2008). Therefore, microalgae are considered as a promising substitute for fossil fuels in the future (Li et al., 2010).

Phosphorus is one of the most important nutrient in domestic waste-water. It is difficult to remove and hence along with nitrogen is responsible for eutrophication of water bodies, especially where untreated sewage is discharged. Nutrient removal is becoming a regular approach for wastewater treatment plant, since excess nitrogen and phosphorus in discharged wastewater can lead to downstream eutrophication and ecosystem damage (Swati et al., 2017).

Based on these considerations, it is clear that the only way to obtain an economically and environmentally sustainable microalgal biofuels production is to recycle the nutrients, the majority of which is not included in the lipid fraction destined to biofuels, and remains in the residuals. This possibility is clearly highly connected with the method employed for biomass treatment after harvesting (Sialve et al., 2009; Heilmann et al., 2011; Biller et al., 2012; Rösch et al., 2012; Garcia Alba et al., 2013; Levine et al., 2013; López Barreiro et al., 2013; Zhang et al., 2014; Ward et al., 2014; Barbera, 2016).

Microalgae growth is possible under heterotrophic or mixotrophic conditions as well as autotrophic conditions depending on specific characteristics of the species (Andrade and Costa, 2007) and some microalgae species like Chlorella vulgaris (Mitra et al., 2012), Haematococcus pluvialis (Kobayashi et al., 1992), Spirulina platensis (Marquez et al., 1993), C. sorokiniana (Wang et al., 2012), Botryococcus braunii (Zhang et al., 2011), and C. zofingiensis (Liu et al., 2011) have been observed under autotrophy, heterotrophy, and mixotrophy conditions. Mixotrophic cultivation of microalgae provides higher biomass and lipid productivities than cultivation under photoautotrophic conditions, the cost of the organic carbon substrate is estimated to be about $80 \%$ of the total cost of the cultivation medium (Bhatnagar et al., 2011).

The objective of this study was to quantify some biochemical changes (lipids, chlorophyll-a and -b, carotenoids and total carbohydrate and removal of nutrients) in mixotrophic condition (glucose substrate) of Chlorella vulgaris grown in nitrate-phosphate rich conditions. Nitrate and phosphate concentrations were measured on the initial and final days of cultivation to evaluate nutrient removal rates. Therefore, the aim of the present study was to determine nutrient uptake performance and efficiency of Chlorella cells under the nutrient rich mixotrophic medium for the future algae-based wastewater treatment application.

\section{Material and Methods}

\section{Algal Growth Medium and Experimental Design}

C. vulgaris was obtained from the Culture Collection of Microalgae at the University of Ege, Izmir, Turkey. The modified and non-modified BG-11 medium were used as the growth medium in the experiments. The growth and nutrient uptake experiments were conducted at four different nutrient levels as presented in Table $1 . \mathrm{NO}_{3}-\mathrm{N}\left(\mathrm{NaNO}_{3}\right)$ and $\mathrm{PO}_{4}-\mathrm{P}\left(\mathrm{K}_{2} \mathrm{HPO}_{4}\right)$ were used as the nitrogen and phosphorus sources, respectively. A standard initial inoculum of the algae was inoculated to culture flasks $(200 \mathrm{~mL}$ each) that contained BG-11 medium and incubated at $28 \pm 1^{\circ} \mathrm{C}$ under $14 \mathrm{~h}$ light (20 E m${ }^{-2} \mathrm{~s}^{-1} \pm 20 \%$ ), with magnetic stirring (100 rpm). For mixotrophic cultures, glucose was added to the culture broth in concentration of $10 \mathrm{~g} \mathrm{~L}^{-1}$ maintaining the same L/D photoperiod of 14:10 h. BG11 medium and BG11 medium containing glucose were used for autotrophic culture and mixotrophic culture of Chlorella cells, respectively. $10 \mathrm{~g} \mathrm{~L}^{-1}$ glucose has been proved to be an ideal organic matter source for the mixotrophic cultivation of microalgae in some previous studies (Liang et al., 2009; Cheirsilp \& Torpee, 2012). To examine the removal effect of nitrogen and phosphorus from modified medium by using $C$. vulgaris cells, the selected microalgae were triplicate cultured in medium with 0 , $50,100,200 \mathrm{mg} \mathrm{L}^{-1}$ concentration of nitrate and phosphate for 10 days. The initial $\mathrm{pH}$ was adjusted to 7 using $10 \% \mathrm{HCl}$ and the contents of chlorophyll-a, chlorophyll-b, lipid and carotenoids in the supernatant were determined by UV-VIS spectroscopy. 
Table 1. Initial nutrient levels for batch experiments with $C$. vulgaris.

\begin{tabular}{lccc}
\hline Experiment & $\mathbf{N O}_{3}-\mathbf{N}(\mathbf{m g} / \mathbf{L})$ & $\mathbf{P O}_{4}-\mathbf{P}(\mathbf{m g} / \mathbf{L})$ & Glucose $(\mathbf{g} / \mathbf{L})$ \\
\hline Control* (n-mm Bg-11) & $0.06 \pm 0.003$ & $0.001 \pm 0.001$ & No glucose \\
& 0 & 0 & $10 \pm 0.01$ \\
mm BG-11 & $50 \pm 0.24$ & $50 \pm 0.77$ & $10 \pm 0.04$ \\
& $100 \pm 0.58$ & $100 \pm 0.96$ & $10 \pm 0.05$ \\
& $200 \pm 1.33$ & $200 \pm 1.46$ & $10 \pm 0.01$ \\
\hline
\end{tabular}

*Key to subscripts: n-mm: non modified medium, mm: modified medium.

\section{Determination of Chlorophyll and Total Carotenoids Concentration}

Chlorophylls and carotenoids in C. vulgaris were extracted with methanol and spectrophotometrically determined as described by Dere et al. (1998). Total pigment content was obtained by summing chlorophylls and carotenoids contents

\section{Lipid Analysis}

Lipid contents of the microalgae were directly measured by sulpho-phospho-vanillin (SPV) colorimetric method (Mishra et al., 2014). At the end of the cultivation, algal biomass was harvested to measure lipid content. The relationship between the lipid content of the $100 \mu \mathrm{L}$ microalgae suspensions and the absorbency at $530 \mathrm{~nm}$ was acquired from a previous study (Tao et al., 2017; Eq. 1):

$$
\text { Lipid }(\mathrm{mg})=0.123 \mathrm{X} \mathrm{OD}_{530}+0.003\left(\mathrm{R}^{2}=0.999\right)
$$

\section{Dry Weight and Nutrient Removal Analysis}

The dry weight of algal biomass was determined using the method of suspended solid (SS) measurement. For the measurement of water quality, the algal culture was centrifuged $\left(10.000 \mathrm{rpm}\right.$ X $10 \mathrm{~min}$ at $\left.4^{\circ} \mathrm{C}\right)$ and filtered through a 0.45 $\mu \mathrm{m}$ filter. After that, the weight of $C$. vulgaris was calculated from the calibration curve that obtained from the dry cell weight method (Eaton, 2005). The filtered supernatant was then used for the determination of nitrate and phosphate concentrations. To determine nutrient removal rates, $\mathrm{NH}_{3}{ }^{+}-$ $\mathrm{N}$ and $\mathrm{PO}_{4}{ }^{3-}-\mathrm{P}$ were measured on initial and final days of the experimental period. The samples were filtered with a $0.2-$ $\mu \mathrm{m}$ pore-size membrane filter prior to the measurement to exclude suspended materials. Nutrient removal rate (R, \%; Eq. 2) and removal capacities (q, mg/L day, Eq. 3) were calculated as (Babaei et al., 2013):

$$
\begin{aligned}
& \mathrm{R}=100 \times\left(\mathrm{C}_{\mathrm{i}}-\mathrm{C}_{\mathrm{f}}\right) / \mathrm{C}_{\mathrm{i}}, \\
& \mathrm{q}(\mathrm{mg} / \mathrm{L} \text { day })=\left(\mathrm{C}_{\mathrm{i}}-\mathrm{C}_{\mathrm{f}}\right) \times \mathrm{V} / \mathrm{m}
\end{aligned}
$$

V: Solution volume $(\mathrm{mL})$

$\mathrm{m}$ : Dry weight of the adsorbent $(\mathrm{g})$
$\mathrm{C}_{\mathrm{i}}$ and $\mathrm{C}_{\mathrm{f}}$ : initial and final nutrient concentrations of $\mathrm{NH}_{3}{ }^{+}-$ $\mathrm{N}$ or $\mathrm{PO}_{4}{ }^{3-}-\mathrm{P}$ on initial and final days of the experimental period, respectively.

All experiments were performed in 3 replicates. The data are presented as the mean \pm standard deviation of the mean (SDM).

\section{Results and Discussion}

\section{Chlorophyll-a and $b$ and Carotenoid Contents}

In this work, the effects of mixotrophic medium, which is contain high concentration of nitrate and phosphate, were systematically investigated on $C$. vulgaris, regarding the nutrient uptake, the lipid productivity, the chlorophyll, carotenoid and carbohydrate content.

Chl-a and $\mathrm{b}$ and carotenoid levels for the control group were measured $0.6565,0.9883$ and $0.0985 \mu \mathrm{g} / \mathrm{L}$, respectively under mixotrophic cultivation. At the end of the experiment, the highest chlorophyll-a and $-\mathrm{b}$ and carotenoid contents were observed in the $50 \mathrm{mg} \mathrm{L}^{-1}\left(1.33 \mu \mathrm{g} \mathrm{L}^{-1}\right)$ and $50 \mathrm{mg} \mathrm{L}^{-1}$ $\left(2.24 \mu \mathrm{g} \mathrm{L}^{-1}\right)$ and $100 \mathrm{mg} \mathrm{L}^{-1}\left(3.57 \mu \mathrm{g} \mathrm{L}^{-1}\right)$, respectively. Measurements for the Chl-a and $\mathrm{b}$ and carotenoid content, for the $100 \mathrm{mg} \mathrm{L}^{-1}$ and $50 \mathrm{mg} \mathrm{L}^{-1}$ concentration of nitrate and phosphate solution, showed that the high concentration of $\mathrm{NO}_{3}{ }^{-}$and $\mathrm{PO}_{4}{ }^{3-}$ treatment causing an increase in Chl-a and b and carotenoid, respectively (Figure 1). Chlorophyll content results showed that $100 \mathrm{mg} \mathrm{L}^{-1}$ nitrate treatment caused an increase in Chl-a and b and carotenoid levels, while $50 \mathrm{mg}$ $\mathrm{L}^{-1}$ phosphate treatment decreased.

Chlorophyll is one of the cellular compounds on the basis of which microalgal biomass in the culture is estimated and it can be used to measure cell growth (Kong et al., 2013). According to a previous report, the utilization of an external organic carbon source may affect the photoautotrophic growth processes, such as photosynthesis and respiration (Kong et al., 2013). As shown in Figure 1, the effect of glucose and $100 \mathrm{mg} \mathrm{L}^{-1}$ and $50 \mathrm{mg} \mathrm{L}^{-1}$ concentration of nitrate and phosphate solution on the photosynthetic pigment content and 
productivity of mixotrophic $C$. vulgaris was significant. Our results showed that the mixotrophic cultures experience an increase in photosynthetic pigment productivity that was dependent on the increase of high concentration of nutrient in the medium content (Kong et al., 2013).

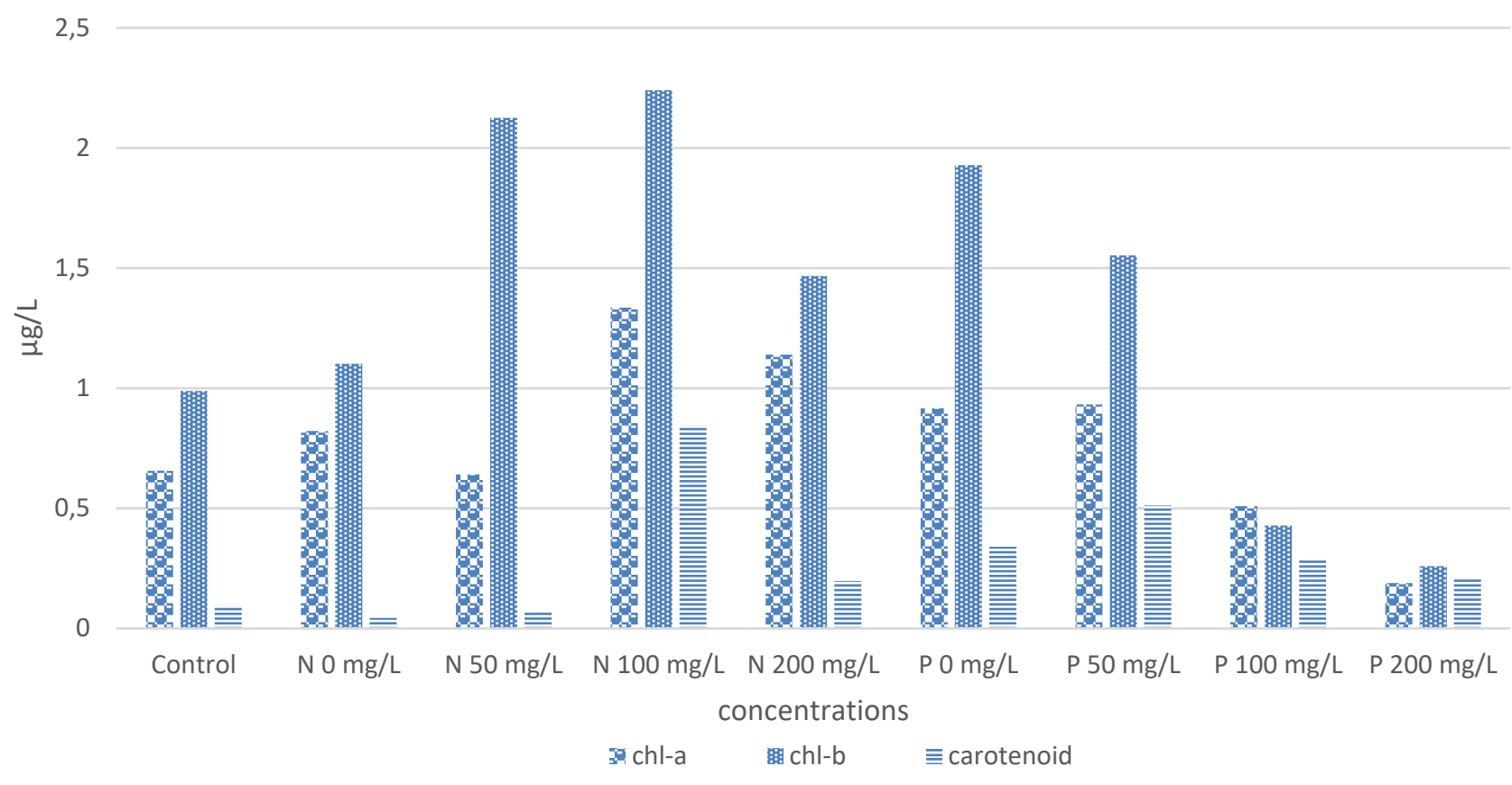

Figure 1. Chl-a and $\mathrm{b}$ and carotenoid changes in $\mu \mathrm{g} / \mathrm{L}$

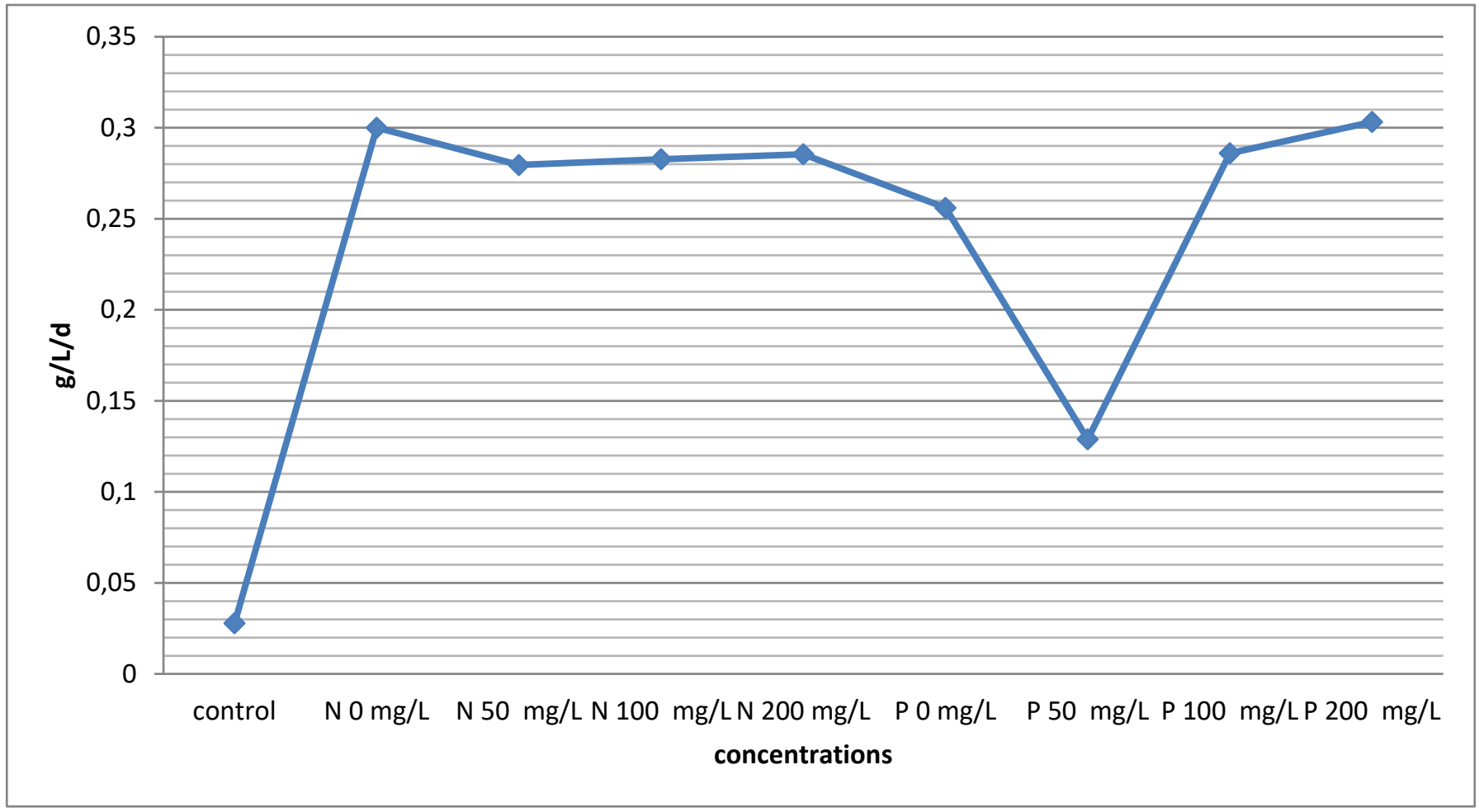

Figure 2. Carbohydrate content changes in $\mathrm{g} / \mathrm{L}$ after the nutrient treatment 


\section{Total Carbohydrate Contents}

The effects of high concentrations of nutrient on the carbohydrate content and productivity of $C$. vulgaris under mixotrophic cultivation can be seen in Figure 2. Carbohydrate content for the control group were measured $0.0278 \mathrm{~g} \mathrm{~L}^{-1}$ under mixotrophic culture conditions. Measurements for the carbohydrate content, for the $200 \mathrm{mg} \mathrm{L}^{-1}$ concentration of nitrate and phosphate solution, showed that the high concentration of $\mathrm{NO}_{3}{ }^{-}$and $\mathrm{PO}_{4}{ }^{3-}$ in the culture media causing an increase in carbohydrate, respectively. The average carbohydrate content for nitrate and phosphate treatment measured as 0.2869 and $0.2435 \mathrm{~g} \mathrm{~L}^{-1}$, showing that these nutrients cause an increase on the increasing concentrations.

Carbohydrates are found as the intermediary reserves in some algae, due to the fact that they are required when the nitrogen becomes limited in the lipid synthesis (Kong et al., 2013). In the present study, when chlorophyll content in C. vulgaris increased, both lipid and carbohydrate content increased by nitrogen depletion. A common trend can be since, in which the carbohydrate content increased rapidly after the nitrogen source concentration decreased to the lowest level, which is consistent with previous findings showing that carbohydrate accumulation in microalgae is often triggered by nitrogen depletion (Orus et al., 1991; Kong et al., 2013). These results suggested that changes in the cellular biochemical composition were influenced by the trophic conditions and nutrient concentration in the medium.

\section{Result of Lipid Analysis}

The measurements for the lipid content for the different nutrient concentration treatment showed that $\mathrm{NO}_{3}{ }^{-}$and $\mathrm{PO}_{4}{ }^{3-}$ treatment causing an increase in lipid levels. The max. lipid content was 27.95 and $29.53 \mathrm{mg} \mathrm{L}^{-1}$ under nitrate and phosphate treatment medium, respectively (Figure 3). Woertz et al. (2009) studied the lipid productivity and nutrient removal by green algae including Scenedesmus, Chlorella and Glolenkinia species grown during the wastewater treatment in batch cultures and reported that the maximum lipid content range was $14-29 \%$ and volumetric productivity of lipid was $17 \mathrm{mg} / \mathrm{L} / \mathrm{d}$. The highest lipid content (30.74 and 39.88 $\mathrm{mg} \mathrm{L}^{-1}$ ) occurred in mixotrophic cultivation when the culture was loaded with a high concentration of nitrate and phosphate (100-200 $\left.\mathrm{mg} \mathrm{L}^{-1}\right)$, higher than under autotrophic cultivation.

The lipid productivity obtained in the present work was not necessarily superior or inferior to those reported elsewhere using different strains of microalgae. For instance, Converti et al. (2009) and Woertz et al. (2009) reported that C. vulgaris growing in Bold's basal medium had somewhat higher production rates ranging from 8 to $20 \mathrm{mg} / \mathrm{d} / \mathrm{L}$ and 17 to 24 $\mathrm{mg} / \mathrm{d} / \mathrm{L}$, respectively. This suggests that in laboratory culture mode the lipid productivity in wastewater or simulated wastewater might be improved by continuous supplementation of nutrients such as nitrate or phosphate (Wang, 2012).

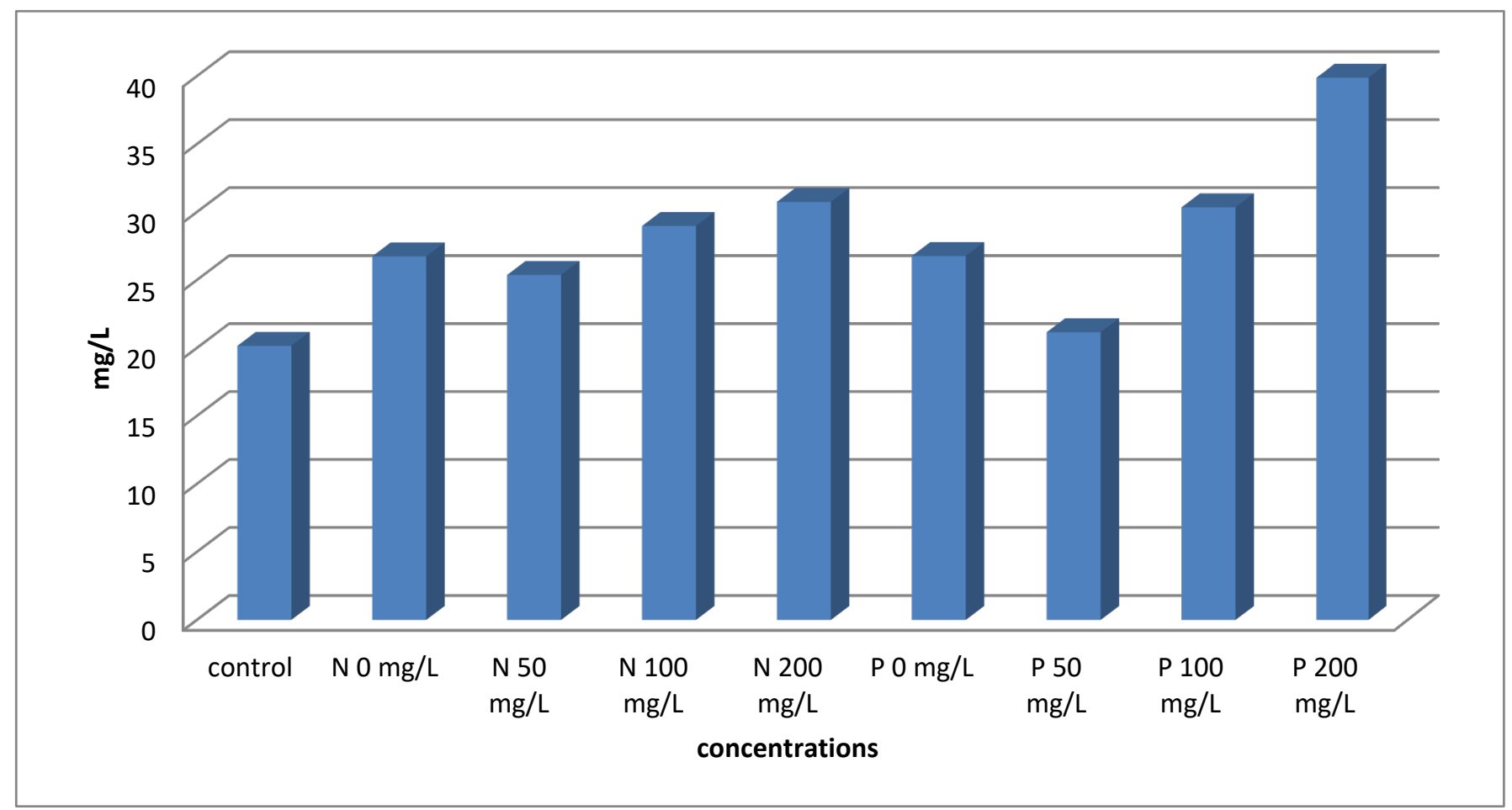

Figure 3. Lipid content changes in $\mathrm{mg} / \mathrm{L}$ after the nutrient treatment 


\section{Nutrient Removal Efficiencies}

The removal amounts and removal efficiency of total nitrogen and phosphorus depending on the four different concentration of culture medium are presented in Figures 4 and 5. The min. and max. nitrate removal amounts and efficiency were $0.2302-0.3584 \mathrm{mg} \mathrm{L}^{-1}$ and $63.61-99.05 \%$ under mixotrophic conditions, respectively. The results showed that the mixotrophic cultures experience an increase in nitrate uptake that was dependent on the increase of high concentration of nutrient in the medium content. The $\mathrm{NO}_{3}{ }^{-}$uptake capacities was average $88.29 \%$. It means that mixotrophic microalgae approximately consumed about $89 \%$ of the initial nitrate after 10 days to produce biomass.

Max. phosphate removal amount and efficiency were also high, as great as $0.2226 \mathrm{mg} \mathrm{L}^{-1}$ and $63.77 \%$ in mixotrophic conditions compared to the other concentration of culture medium at $50 \mathrm{mg} \mathrm{L}^{-1}$ nitrate concentration of nutrient in the medium content. Lowest phosphate removal capacity was observed in 100 and $200 \mathrm{mg} \mathrm{L}^{-1}$ concentration of treatment.
This might be to the fact that the organic carbon concentrations in this experiment were low compared to those in the reviewed literature de-Bashan et al. 2011.

Under the mixotrophic and optimum conditions $(200 \mu \mathrm{mol}$ photon $\mathrm{m}^{-2} \mathrm{~s}^{-1} 16 \mathrm{~h}$ photoperiod and $28 \%$ inoculum size), $63.61-99.05 \%$ of $\mathrm{NO}_{3}{ }^{-}$and $13.97-63.77 \%$ of $\mathrm{PO}_{4}{ }^{3-}$ were successfully removed (Tab 2).

Mixotrophic cell cultivation utilizing both light and organic carbon source has been considered the most efficient process for the production of microalgal biomass (Lee et al., 1996). When the light energy used for $\mathrm{CO}_{2}$ fixation is decreased in mixotrophic cultures, most of the energy is used for carbon assimilation. Therefore, since the amount of energy dissipated is minimal, mixotrophy provides higher energetic efficiency than other cultivation modes (Lalucat et al., 1984). On the other hand, Shi et al. (2000) reported that glucose can be considered the best organic C-substrate for the growth of Chlorella.

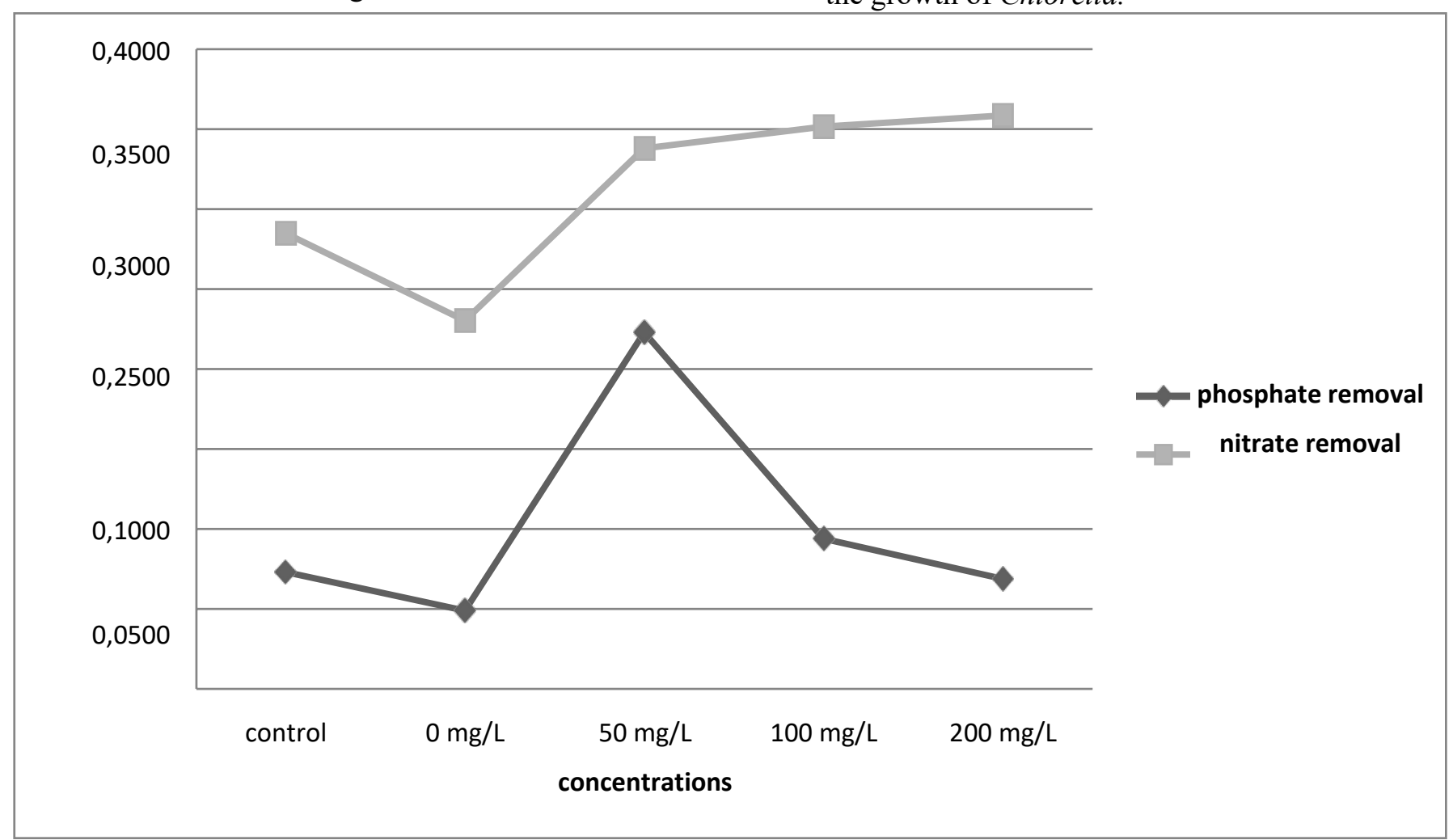

Figure 4. Nutrient removal levels measured for $0 ; 50 ; 100 ; 200 \mathrm{mg} \mathrm{L}^{-1}$ and control values. 


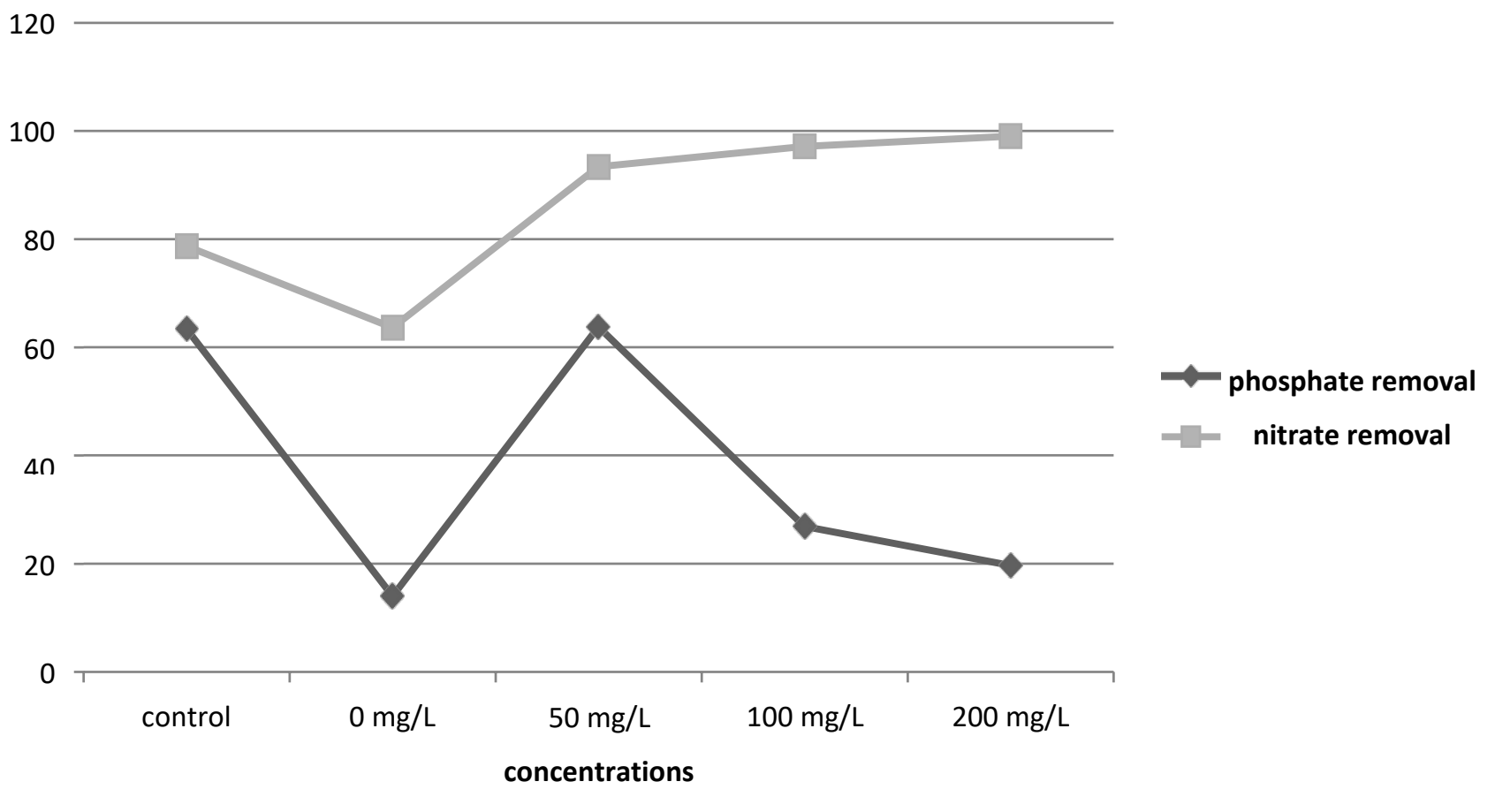

Figure 5. Nutrient removal efficiency of $C$. vulgaris under the mixotrophic conditions

Under the mixotrophic and optimum conditions $(200 \mu \mathrm{mol}$ photon $\mathrm{m}^{-2} \mathrm{~s}^{-1} 16 \mathrm{~h}$ photoperiod and $28 \%$ inoculum size), $63.61-99.05 \%$ of $\mathrm{NO}_{3}{ }^{-}$and $13.97-63.77 \%$ of $\mathrm{PO}_{4}{ }^{3-}$ were successfully removed (Tab 2).

Mixotrophic cell cultivation utilizing both light and organic carbon source has been considered the most efficient process for the production of microalgal biomass (Lee et al., 1996). When the light energy used for $\mathrm{CO}_{2}$ fixation is decreased in mixotrophic cultures, most of the energy is used for carbon assimilation. Therefore, since the amount of energy dissipated is minimal, mixotrophy provides higher energetic efficiency than other cultivation modes (Lalucat et al., 1984). On the other hand, Shi et al. (2000) reported that glucose can be considered the best organic C-substrate for the growth of Chlorella.

\section{Conclusion}

To conclude, this study describes the nutrient removal efficiency of $C$. vulgaris under the mixotrophic conditions while illustrating the effect of high concentration of nitrate and phosphate solution on carbohydrate, chlorophyll and carotenoid content as well as its relation between lipid synthesis levels. The findings from the study show that the uptake of nutrient with $C$. vulgaris green microalgae for excess nitrogen and phosphorus removal is effective. Generally, $C$. vulgaris removed more nutrients from mixotrophic medium than the control medium. Uptake of nitrate by the culture was the highest under mixotrophic conditions than the autotrophic conditions (control medium) at $0,50,100$ or $200 \mathrm{mg}$ $\mathrm{L}^{-1}$ nutrient concentrations. Uptake of phosphate was higher under autotrophic conditions at $50 \mathrm{mg} \mathrm{L}^{-1}$ nutrient concentrations. It was concluded that the mixotrophic regime, using glucose, is superior to autotrophic regime for the uptake of nitrate. The activity of $C$. vulgaris microalgae on practical aqueous solution nutrient removal will reduce drastically the concentration of excess nitrogen that will be discharged into the various compartments of the environment, and can even find use in agricultural farms as irrigation water. 
Table 2. Standardized conditions (control) and under high concentration of nitrate and phosphate treatment from the 10th day of mixotrophic culture condition. Values are expressed as amount of substances in relation to the dry matter. Each value represents the mean of three replicates \pm standard deviation.

\begin{tabular}{|c|c|c|c|c|c|c|c|}
\hline & Chl-a $(\mu \mathrm{g} / \mathrm{L})$ & Chl-b $(\mu \mathrm{g} / \mathrm{L})$ & $\begin{array}{c}\text { Carotenoid } \\
(\mu \mathrm{g} / \mathrm{L})\end{array}$ & $\begin{array}{c}\text { Carbohydrate } \\
(\mathrm{g} / \mathrm{L})\end{array}$ & $\begin{array}{c}\text { Lipid } \\
(\mathrm{mg} / \mathrm{L})\end{array}$ & $\begin{array}{c}\text { Adsorption } \\
\text { capacities } \\
(\mathrm{mg} / \mathrm{L})\end{array}$ & $\begin{array}{c}\text { Uptake } \\
\text { efficiency } \\
(\%)\end{array}$ \\
\hline Control & $0.6565 \pm 0.006$ & $0.9883 \pm 0.005$ & $0.0945 \pm 0.004$ & $0.027 \pm 0.004$ & $20.15 \pm 0.3$ & $0.1788 \pm 0.001$ & $71.04 \pm 0.1$ \\
\hline N 0 mg/L & $0.82181 \pm 0.005$ & $1.1019 \pm 0.007$ & 0.004 & $0.3000 \pm 0.004$ & $26.73 \pm 0.9$ & $0.2302 \pm 0.002$ & $63.61 \pm 0.4$ \\
\hline $\mathrm{N} 50 \mathrm{mg} / \mathrm{L}$ & $0.6408 \pm 0.002$ & $2.1255 \pm 0.006$ & $0.0689 \pm 0.006$ & $0.2795 \pm 0.005$ & $25.36 \pm 0.2$ & $0.3379 \pm 0.005$ & $93.35 \pm 0.1$ \\
\hline N $100 \mathrm{mg} / \mathrm{L}$ & $1.3348 \pm 0.005$ & $2.2404 \pm 0.004$ & $0.8437 \pm 0.006$ & $0.2827 \pm 0.006$ & $28.96 \pm 0.9$ & $0.3515 \pm 0.005$ & $97.13 \pm 0.3$ \\
\hline N $200 \mathrm{mg} / \mathrm{L}$ & 1.139 & $1.4674 \pm 0.005$ & $0.1974 \pm 0.004$ & $0.2854 \pm 0.002$ & $30.74 \pm 0.7$ & $0.3585 \pm 0.002$ & \pm 0.3 \\
\hline$P 0 \mathrm{mg} / \mathrm{L}$ & $0.9163 \pm 0.006$ & $1.9277 \pm 0.006$ & $0.3396 \pm 0.001$ & $0.001 \pm 0.001$ & $26.75 \pm 0.9$ & $0.0488 \pm 0.003$ & $13.97 \pm 0.5$ \\
\hline P $50 \mathrm{mg} / \mathrm{L}$ & $0.9317 \pm 0.004$ & $1.5525 \pm 0.002$ & $0.5120 \pm 0.001$ & $0.1288 \pm 0.002$ & $21.15 \pm 0.9$ & $0.2227 \pm 0.004$ & $63.76 \pm 0.3$ \\
\hline$P 100 \mathrm{mg} / \mathrm{L}$ & $0.5087 \pm 0.004$ & $0.4285 \pm 0.003$ & $0.2891 \pm 0.006$ & $0.2860 \pm 0.001$ & $30.34 \pm 0.8$ & $0.0938 \pm 0.004$ & $26.85 \pm 0.6$ \\
\hline P $200 \mathrm{mg} / \mathrm{L}$ & 0.18 & $0.2589 \pm 0.003$ & $0.2096 \pm 0.005$ & $0.3032 \pm 0.004$ & $39.88 \pm 0.4$ & $0.0686 \pm 0.003$ & $19.65 \pm 0.1$ \\
\hline
\end{tabular}

\section{Compliance with Ethical Standard}

Conflict of interests: The authors declare that for this article they have no actual, potential or perceived conflict of interests.

Ethics committee approval: There is no need ethics committee approval.

Financial disclosure: This research was funded by the Manisa Celal Bayar University Scientific Investigation Project, Grant Nr. FEF 2015-154, Manisa, Turkey.

\section{References}

Abe, K., Takahashi, E., Hirano, M. (2008). Development of laboratory-scale photobioreactor for water purification by use of a biofilter composed of the aerial microalga Trentepohlia aurea (Chlorophyta). Journal of Applied Phycology, 20, 283-288.

https://doi.org/10.1007/s10811-007-9245-9

Andrade, M.R., Costa, J.A.V. (2007). Mixotrophic cultivation of microalga Spirulina platensis using molasses as organic substrate. Aquaculture, 264(1-4), 130-134.

https://doi.org/10.1016/j.aquaculture.2006.11.021

Eaton, A.D. (2005). Standard Methods for the Examination of Water and Wastewater. 21st edition. Washington, DC: American Public Health Association. APHA, AWWA, WEF. ISBN: 0875530478
Azianabiha, A.H.K., Zahira, Y., Siti, R.S.A., Mohd, S.T. (2019). Assessing the feasibility of microalgae cultivation in agricultural wastewater: The nutrient characteristics. Environmental Technology and Innovation, 15, 1-10.

https://doi.org/10.1016/j.eti.2019.100402

Babaei1, A.A., Azadi, R., Jaafarzadeh, N., Alavi, N. (2013). Application and kinetic evaluation of upflow anaerobic biofilm reactor for nitrogen removal from wastewater by Anammox process. Iranian Journal of Environmental Health Science, 10(1), 20-36.

https://doi.org/10.1186/1735-2746-10-20

Barbera, E., Sforza, E., Kumar, S., Morosinotto, T., Bertucco, A. (2016). Cultivation of Scenedesmus obliquus in liquid hydrolysate from flash hydrolysis for nutrient recycling. Bioresource Technology, 207, 59-66.

https://doi.org/10.1016/j.biortech.2016.01.103

Bhatnagara, A., Kumara, E., Sillanpää, M. (2011). Fluoride removal from water by adsorption-A review. Chemical Engineering Journal, 171(3), 811-840.

https://doi.org/10.1016/j.cej.2011.05.028

Biller, P., Ross, A.B., Skill, S.C., Lea-Langton, A., Balasundaram, B., Hall, C., Riley, R., Llewellyn, C.A. (2012). Nutrient recycling of aqueous phase for microalgae cultivation from the hydrothermal liquefaction process. Algal Research, 1(1), 70-76. 
https://doi.org/10.1016/j.algal.2012.02.002

Bruce, E.R. (2008). Opportunities for renewable bioenergy using microorganisms. Biotechnology and Bioengineering, 100(2), 203-212.

https://doi.org/10.1002/bit.21875

Cheirsilp, B., Torpee, S. (2012). Enhanced growth and lipid production of microalgae under mixotrophic culture condition: effect of light intensity, glucose concentration and fedbatch cultivation. Bioresource Technology, 110, 510-516. https://doi.org/10.1016/j.biortech.2012.01.125

Chisti, Y. (2008). Biodiesel from microalgae beats bioethanol. Trends in Biotechnology, 26(3), 126-131.

https://doi.org/10.1016/j.tibtech.2007.12.002

Converti, A., Casazza, A.A., Ortiz, E.Y., Perego, P., Borghi M.D. (2009). Effect of temperature and nitrogen concentration on the growth and lipid content of Nannochloropsis oculata and Chlorella vulgaris for biodiesel production. Chemical Engineering and Processing: Process Intensification, 48(6), 1146-1151.

https://doi.org/10.1016/j.cep.2009.03.006

Dere, S., Günes, T., Sivaci, R. (1998). Spectrophotometric determination of chlorophyll-a, b and total carotenoid contents of some algae species using different solvents. Turkish Journal of Botany, 22(1), 13-17.

Garcia Alba, L., Torri, C., Fabbri, D., Kersten, S.R.A. \& Brilman, D.W.F. (2013). Microalgae growth on the aqueous phase from Hydrothermal Liquefaction of the same microalgae. Chemical Engineering Journal, 228, 214-223.

https://doi.org/10.1016/j.cej.2013.04.097

Groom, M.J., Gray, E.M., Townsend, P.A. (2008). Biofuels and biodiversity: principles for creating better policies for biofuel production. Conservation Biology, 22(3), 602-609. https://doi.org/10.1111/j.1523-1739.2007.00879.x

Heilmann, S.M., Jader, L.R., Harned, L.A., Sadowsky, M.J., Schendel, F.J., Lefebvre, P.A., von Keitz, M.G., Valentas, K.J. (2011). Hydrothermal carbonization of microalgae II. Fatty acid, char, and algal nutrient products. Application Energy, 88(10), 3286-3290. https://doi.org/10.1016/j.apenergy.2010.12.041

Khan, M., Yoshida, N. (2008). Effect of 1-glutamic acid on the growth and ammonium removal from ammonium solution and natural wastewater by Chlorella vulgaris NTM06. Bioresource Technology, 99, 575-582.

https://doi.org/10.1016/j.biortech.2006.12.031

Kobayashi, M., Kakizono, T., Nishio, N., Nagai, S. (1992). Effects of light intensity, light quality and illumination cycle on astaxanthin formation in a green alga, Haematococcus pluvialis. Journal of Fermentation and Bioengineering, 74(1), 61-63.

https://doi.org/10.1016/0922-338X(92)90271-U

Kong, W.B., Yang, H., Cao, Y.T., Song, H., Hua, S.F., Xia, C.G. (2013). Effect of glycerol and glucose on the enhancement of biomass, lipid and soluble carbohydrate production by Chlorella vulgaris in mixotrophic culture. Food Technology and Biotechnology, 51(1), 62-69.

Lalucat, J., Imperial, J., Pares, R. (1984). Utilization of light for the assimilation of organic matter in Chlorella sp. VJ79. Biotechnology and Bioengineering, 26(7), 677-681. https://doi.org/10.1002/bit.260260707

Lee, Y.K., Ding, S.Y., Hoe, C.H., Low, C.S. (1996). Mixotrophic growth of Chlorella sorokiniana in outdoor enclosed photobioreactor. Journal of Applied Phycology, 8(2), 163169.

https://doi.org/10.1007/BF02186320

Levine, R.B., Sambolin Sierra, C.O., Hockstad, R., Obeid, W., Hatcher, P.G., Savage, P.E. (2013). The use of hydrothermal carbonization to recycle nutrients in algal biofuel production. Environmental Progress and Sustainable Energy, 32(4), 962-975.

https://doi.org/10.1002/ep.11812

Liang, Y., Sarkany, N., Cui, Y. (2009). Biomass and lipid productivities of Chlorella vulgaris under autotrophic, heterotrophic and mixotrophic growth conditions. Biotechnology Letters, 31(2), 1043-1049.

https://doi.org/10.1007/s10529-009-9975-7 
Liu, J., Huanga, J., Sun, Z., Zhong, Y., Jiang, Y., Chen, F. (2011). Differential lipid and fatty acid profiles of photoautotrophic and heterotrophic Chlorella zofingiensis: Assessment of algal oils for biodiesel production. Bioresource Technology, 102(1), 106-110.

https://doi.org/10.1016/j.biortech.2010.06.017

Li, X., Hu, H., Gan, K., Sun, Y. (2010). Effects of different nitrogen and phosphorus concentrations on the growth, nutrient uptake, and lipid accumulation of a freshwater microalga Scenedesmus sp. Bioresource Technology, 101(14), 5494-5500.

https://doi.org/10.1016/j.biortech.2010.02.016

López Barreiro, D., Prins, W., Ronsse, F., Brilman, W. (2013). Hydrothermal liquefaction (HTL) of microalgae for biofuel production: state of the art review and future prospects. Biomass Bioenergy, 53(2013), 113-127.

https://doi.org/10.1016/j.biombioe.2012.12.029

Marquez, J., Sasaki, K., Kakizono, T., Nishio, N., Nagai, S. (1993). Growth characteristics of Spirulina platensis in mixotrophic and heterotrophic condtions. Journal of Fermentation and Bioengineering, 76(5), 408-410.

https://doi.org/10.1016/0922-338X(93)90034-6

Mishra, S.K., Suh, W.I., Farooq, W., Moon, M., Shrivastav, A., Park, M.S., Yang, J.W. (2014). Rapid quantification of microalgal lipids in aqueous medium by a simple colorimetric method. Bioresource Technology, 155(2014), 330-333.

https://doi.org/10.1016/j.biortech.2013.12.077

Mitra, D., Lamsal, B.P. (2012). Heterotrophic/mixotrophic cultivation of oleaginous Chlorella vulgaris on industrial coproducts. Algal Research, 1(1), 40-48.

https://doi.org/10.1016/j.algal.2012.03.002

Orús, M.L., Marco, E., Martínez, F. (1991). Suitability of Chlorella vulgaris UAM 101 for heterotrophic biomass production. Bioresource Technology, 38(1991), 179-184.

https://doi.org/10.1016/0960-8524(91)90151-9

Perez-Garcia, O., Bashan, Y., Esther Puente, M. (2011). Organic carbon supplementation of sterilized municipal wastewater is essential for heterotrophic growth and removing ammonium by the microalga Chlorella vulgaris. Journal of Phycology, 47(1), 190-199.

https://doi.org/10.1111/j.1529-8817.2010.00934.x

Rösch, C., Skarka, J., Wegerer, N. (2012). Materials flow modeling of nutrient recycling in biodiesel production from microalgae. Bioresource Technology, 107(2012), 191-199. https://doi.org/10.1016/j.biortech.2011.12.016

Shi, X.M., Zhang, X.W., Chen, F. (2000). Heterotrophic production of biomass and lutein by Chlorella protothecoides on various nitrogen sources. Enzyme and Microbial Technology, 27(3-5), 312-318.

https://doi.org/10.1016/S0141-0229(00)00208-8

Sialve, B., Bernet, N., Bernard, O. (2009). Anaerobic digestion of microalgae as a necessary step to make microalgal biodiesel sustainable. Biotechnological Advances, 27(4), 409-416.

https://doi.org/10.1016/j.biotechadv.2009.03.001

Skoog, D., Holler, F., Nieman, T., Kılıç, E., Köseoğlu, F. (2000). Enstrümantal Analiz ilkeleri. Ankara, Turkey, Bilim Press., 1038 pp. ISBN 9789755560731

Swati, Y.K., Gayatri, G., Sanjay, N., Kiran, P., Bhaskar, K., Sanjay, K. (2017). Exploiting phosphate-starved cells of Scenedesmus sp. for the treatment of raw sewage. Indian Journal of Microbiology, 57(2), 241-249.

https://doi.org/10.1007/s12088-016-0626-0

Tao, Y.F., Qiang, J., Yin, G.J., Xu, P., Shi, Q., Bao, J.W. (2017). Identification and characterization of lipid metabolism-related microRNAs in the liver of genetically improved farmed tilapia (GIFT, Oreochromis niloticus) by deep sequencing. Fish Shellfish Immunologi. 69(2), 227-235. https://doi.org/10.1016/j.fsi.2017.08.023

Wan, M.X., Wang, R.M., Xia, J.L., Rosenberg, J.N., Nie, Z.Y., Kobayashi, N. (2012). Physiological evaluation of a new Chlorella sorokiniana isolate for its biomass production and lipid accumulation in photoautotrophic and heterotrophic cultures. Biotechnology and Bioengineering, 109(8), 1958-1964.

https://doi.org/10.1002/bit.24477 
Ward, A.J., Lewis, D.M., Green, F.B. (2014). Anaerobic digestion of algae biomass: a review. Algal Research, 5, 204214.

https://doi.org/10.1016/j.algal.2014.02.001

Woertz, I.C., Lundquist, T.J., Feffer, A.S., Nelson, Y.M. (2009). Lipid productivity of algae grown during treatment of dairy and municipal wastewaters. Journal of Environmental Engineering, 135(11), 1115-1122.

https://doi.org/10.1061/(ASCE)EE.1943-7870.0000129
Zhang, H., Wang, W., Li, Y., Yang, W., Shen, G. (2011). Mixotrophic cultivation of Botryococcus braunii. Biomass and Bioenergy, 35(5), 1710-1715.

https://doi.org/10.1016/j.biombioe.2011.01.002

Zhang, Y., Kendall, A., Yuan, J. (2014). A comparison of on-site nutrient and energy recycling technologies in algal oil production. Resources, Conservation and Recycling, 88, 1320.

https://doi.org/10.1016/j.resconrec.2014.04.011 